The paper by Giacchino and his colleagues, on which your recommendations for management are so clearly based, was criticised in the subsequent discussion for its conclusions that colonoscopy should not be performed and it is surprising that you should perpetuate this erroneous conclusion.

There is clearly much evidence to support a co-ordinated approach to the problem of massive bleeding from the large bowel, involving the gastroenterologist, endoscopist, radiologist, and surgeon in a joint and flexible approach to investigation and management rather than adherence to the more rigid flow chart suggested.

RICHARD H HUNT

Department of Gastroenterology,

Royal Naval Hospital,

1 Hunt RH. Clin Gastroenterol 1978;7:719-40.
2 Deyhle P, Blum AL, Neusch HJ, Jenny S. Endoscopy $1974 ; 6: 229-32$.

$1974 ; 6: 229-32$.
3 Rossini FP, Ferrari A. Acta Endoscop 1976;6:165-8.
4 Forde KA. In: Proceedings of Second International Congress on Colonoscopy and Disease of the Large Congress on Colonoscopy and
Bowel. Miami, USA, 1980.

- Boley SJ, Sammartano R, Brandt LJ, Sprayregan S. Surg Gynecol Obstet 1979;149:353-9.

Tarin D, Allison DJ, Modlin IM, Neale G. Br Med $\mathcal{F}$ 1978; ;i :751-4

Giacchino JL, Geis WP, Pickleman JR, Dado DV, Hadock WE, Freeask RJ. Surgery 1979;86:368-76 Rogers BH, Adler F. Gastroenterology 1976;71

\section{Diet and ulcerative colitis}

SIR,-We read with interest the communication of $\mathrm{Dr} J \mathbf{R}$ Thornton and others (2 February, p 293) on diet and ulcerative colitis. Since we had observed that patients with Crohn's disease eat more refined carbohydrates and sugar than their matched controls (177 g/day versus $74 \mathrm{~g} /$ day), ${ }^{1}$ we were interested to know whether patients with ulcerative colitis have the same dietary intake.

The nutritional habits of 114 patients with ulcerative colitis were investigated by means of questionnaire and compared with a control group of 114 persons matched by age, sex, and social status. In contrast to the patients with Crohn's disease patients with ulcerative colitis did not have an increased consumption of refined carbohydrates-94 $\mathrm{g}$ /day versus 78 g/day, which comes very close to Dr Thornton's results. However, they consumed significantly more cereal products and potatoes and significantly less milk products, coffee, tea, fruit juices, vegetables, fruit, and alcohol than the control group. ${ }^{2}$

G A MARTINI A STENNER W J BRANDES

Medizinische Universitătsklinik, D-3550 Marburg,
Federal Republic of Germany

1 Martini GA, Brandes JW. Klin Wschr 1976;54:367-71. Brandes JW, Stenner A, Martini GA. Z Gastroenterol
1979;17:834-42.

\section{Recurrent abdominal pain in childhood}

SIR,-I was interested in reading your leading article about "Recurrent abdominal pain in childhood" (26 April, p 1096).

While I agree with its contents, as a GP I was surprised that you had not mentioned mesenteric adenitis. In my experience this is extremely common in children, it is recurring, and often it is not accompanied by any other abnormal physical signs. There are two other conditions I thought you might have mentioned because they are so common: constipation, and pain in girls nearing menstruation-sometimes a year before it.

These are very common conditions taking up a great deal of our time, but it is very reassuring to know that the huge majority of abdominal pains in children have no serious underlying pathology.

Pinner, Middx HA5 2BS

P C BRUNNER

\section{Distinguishing direct and indirect} inguinal hernias

SIR,-Mr D N L Ralphs and others (12 April, p 1039) have shown clearly how unreliable are the features of distinction between direct and indirect inguinal hernia listed in surgical textbooks, apart from the agreed fact that a scrotal hernia is indirect. The application of certain simple observations, however, can make an accurate distinction in $90 \%$ of cases and has the advantage that the patient is not subjected to the discomfort of digital exploration of the external ring.

Firstly, the common type of direct hernia due to muscular weakness is usually bilateral, although the patient may be aware of only one hernia. Secondly, simultaneous bilateral indirect hernias are uncommon, but the development of a hernia in a patient who has had a previous operation for hernia on the opposite side usually indicates that the hernia is indirect. Thirdly, an indirect hernia may on occasion be difficult to demonstrate without some exertion on the part of the patient and some manipulation is often necessary to reduce it. Lastly, a direct hernia cannot be masked and inevitably appears when the patient stands and rarely requires any manipulation to reduce it when he lies down.

Admittedly the unilateral direct funicular hernia and the "pantaloon" sac of the combined direct and indirect hernia are sources of error, but they comprise only a small percentage of inguinal hernias. Many direct hernias are symptomless and it is surprising how many middle-aged and elderly patients will opt for conservative treatment of direct hernia when assured of its safety by a confident surgeon.

Liverpool L18 3EB

W M BeAtTiE

Prophylaxis of surgical wound sepsis: cardiac pacemakers

SIR,-Your recent leading article (19 April, p 1063) draws attention to points of importance and relevance in the implantation of permanent cardiac pacemakers, where infection may prove hazardous. Most pacemakers are now implanted by the transvenous or endocardial route, ${ }^{12}$ without the need for a thoracotomy. The incidence of infection is of the order of that quoted for other "clean" procedures and varies in reported series from zero to $12 \cdot 6 \% .^{2-5}$ Not only does infection cause considerable suffering and expense but it is also occasionally the cause of death.

The organisms mentioned in your article are responsible for the bulk of pacemaker infections and in those cases infected with Staphylococcus aureus it is considered necessary to explant all foreign material to eradicate the infection. ${ }^{6}$ The patients are often dependent on their pacemaker for an effective ventricular rate and must necessarily be protected by having a second pacemaker implanted before removal of the infected material. This may be a temporary pacemaker or a second permanent system provided there is a clean, safe site for its insertion. ${ }^{4}$ The potential risk of infective endocarditis means that both pulse generator and electrode should be removed. ${ }^{7}$ Sometimes the endocardial lead is firmly adherent to the right ventricle because of fibrosis and can be removed only by right atriotomy. This has proved necessary in persisting or severe infections.?

Most authorities employ prophylactic antibiotics for new primary implantations, although there are many different recommended regimens. ${ }^{8}$ Opinion is still divided over the use of surgical drains for the pulse generator pocket, and over the use of prophylactic antibiotics for pulse generator replacement operations. ${ }^{5} 689$

\section{N Paul Silverton}

\section{University Department of} Leeds LS2 9JT

${ }^{1}$ Fishman NH, Hutchinson JC, Edmunds LH, et al. Am ₹ Surg 1970;120:187-91.

${ }_{2}^{2}$ Am Kohn O. Am Heart $\mathcal{F} 1974 ; 88: 656-63$

Firor WB, Lopez JF, Nanson EM, Mori M. Ann Thorac Surg 1968;6:431-6.

Kenelly BM, Piller LW. Br Heart f 1974 ;36:1133-40 Edhag O, Lagergren H. Ann N Y Acad Sci 1969; 167:76

Jora FM, Toledo-Pereyra L, Lewis JW, et al. I Thorac Cardiovasc Surg 1979;77:298-300.

Lemire GG, Morin JE, Dobell ARC. Can $\mathcal{f}$ Surg $1975 ; 18: 181-4$

artstein AI, Jackson J, Gilbert

Hartstein AI, Jackson J, Gilbert DN. $\mathcal{f}$ Thorac
Cardiovasc Surg 1978;75:219-22.
Richardson PL, Pate JW. $\mathcal{F} A M A$ 1973;225:1388.

\section{Unrecognised dehydration during} parenteral nutrition?

SIR,-We agree with Dr C C Wise's (19 April, p 1086) correction of the osmolality of Glucoplex 1600 quoted in Drs R W G Prescott and J C Stoddart's letter (22 March, p 847) and have found the osmolality (by freezing point depression) of clinically useful amino-acid and glucose mixtures in a bag delivery system using Aminoplex 12 and the Glucoplex solutions (1000 and 1600) range from 1400 to $1900 \mathrm{mmol}(\mathrm{m} 0 \mathrm{smol}) / \mathrm{kg}$. His letter and that of Dr R G Wilkes ( $p$ 1087) indicate that the water derived from the breakdown of glucose to carcon dioxide and the water released in protein synthesis is such that "effective" water content of such intravenous feeding mixtures approaches $100 \%$ if the glucose is "burnt." Indeed, if the carbon chains of amino-acids infused in intravenous feeding preparations are catabolised to carbon dioxide there may even be a net gain of water.

While glucose is the energy source of choice in the severely ill patient it is important to give only those glucose calories which can be metabolised. The blanket figure of $0.8 \mathrm{MJ}$ $(200 \mathrm{kcal})$ per gram of nitrogen should be abandoned. Long et al showed an improvement in nitrogen balance with increasing carbohydrate intake until the calorie value is equivalent to the patient's metabolic rate, although further enhancement of positive nitrogen balance was achieved by adding exogenous insulin. ${ }^{1}$ It should be remembered that the metabolic rate is low in the "ebb" phase of injury and hence such patients may require a calorie: nitrogen ratio of less than 100:1 whereas those in the "flow" phase may utilise in excess of 200:1. The appropriate rate of infusion of calories may be judged by "titrating" the reponse of nitrogen balance against calorie input while maintaining blood glucose 
levels below $10 \mathrm{mmol} / 1(180 \mathrm{mg} / 100 \mathrm{ml})$ or by measuring the metabolic rate.

The true lesson of the week was: Patients should not be given more calories than they can use because when calories are given in excess of this the "dehydration" described by Drs Prescott and Stoddart may occur.

G F BATSTONE

A E GENT

\section{Salisbury General Infirmary, Salisbury SP2 7SX} ${ }^{1}$ Long JM, Wilmore, DW, Mason AD, Pruitt BA.
Ann Surg 1977;185:417-22.

\section{Cerebral atrophy or hydrocephalus?}

SIR,-Dr I W Turnbull (15 March, p 790) supported the call of your leading article ( 9 February, p 348) for a trial to determine the value of cerebrospinal fluid shunting in patients with dementia, gait disturbance, and hydrocephalus. He suggested that, in addition to static computed tomography, dynamic metrizamide cisternography should be the main investigation. We have performed study which would suggest otherwise. ${ }^{1}$

We compared results of preoperative tests (24-hour intraventricular pressure recording cerebrospinal fluid infusion test, ventricular isotope clearance, and cerebral blood flow studies) with the response to shunting in 26 adult patients suspected of having communicating hydrocephalus. The potential of patient to improve after shunting was reliably identified only by the finding of spontaneous waves of increased intracranial pressure, occurring once or twice a minute during the period of continuous monitoring. Similar observations have been made by others. ${ }^{2-5}$ The remaining tests often demonstrated an abnormality but were unreliable as predictors of the outcome in an individual patient. Intracranial pressure measurements should form an integral part of any future trial.

J D PICKARD

Wessex Neurological Centre, Southampton General Hospital, Southampton $\mathrm{SO} 9 \mathrm{XY}$

Graham Teasdale

Institute of Neurological Sciences,

Southern General Hospital,

Glasgow G51 4T

1 Pickard JD, Teasdale G, Matheson M, et al. In: Intracranial pressure IV. Berlin: Springer-Verlag

( Chawla JC, Hulme A, Cooper R. $f$ Neurosurg 1974 40:376-80.

Symor , Dorsch NWC. 7 Neurosurg 1975 ;42:258-73.

Brock $4 \overrightarrow{4}$. Radiologie 1977;17:460-5

- Jensen F, Jensen FT. Acta Neurochir 1979;46:243-57.

\section{Hypnotics and hangover}

SIR,-It is useful for practitioners to be aware of benzodiazepine hypnotics, such as triazolam, with a $r$ :latively short half life. However, other comments about triazolam in your leading article "Hypnotics and Hangover" (15 March, p 743) should be read with caution.

The evidence for the statement that triazolam "is not associated with much detectable hangover" is a single study. ${ }^{1}$ This was a study of young people; it is in older people that adversf effects of hypnotics are most troublesome. Further, it was only a relative lack of has. iver by comparison with flurazepam $30 \mathrm{~m}$ performance on, for example, a card sor, $1 \mathrm{~g}$ test at $2.30 \mathrm{pm}$ the next day in the triazolam $0.5 \mathrm{mg}$ group was still impaired by comparison with the placebo group.

The statement that patients who wake early despite bedtime medication might take in addition triazolam at some point in the night to give them two or three hours' extra sleep is unwise, even though-as your editorial suggests-this advice is only for the "severely depressed." With the appropriate treatment early morning waking is one of the symptoms of severe depression that is the quickest to clear and one which, with sympathetic advice, patients can be helped through. A patient should not be advised to medicate himself when his cognitive processes may already be disturbed by a recent dose of another hypnotic, or to subject himself to yet further hangover the next day.

J CHICK

Royal Edinburgh Hospital

Edinburgh EH10 5HF

Veldkamp W, Straw RN, Metzler CM, Demissianos HV. F Clin Pharmacol 1974;14:102-11.

\section{Chlormethiazole and temazepam}

SIR,-The hypothesis that short half-life hypnotics such as chlormethiazole and temazepam have advantages in the management of insomnia, particularly in the elderly, may well be valid; and the recent paper by $\mathrm{Dr}$ R S Briggs and others (1 March, p 601) would appear to support this view. However, we feel that their experimental evidence and conclusions, which are based on substantially negative findings, may be criticised on the following grounds.

(1) The two-minute abbreviated letter cancellation task which they used to detect impairment of psychomotor performance skills may not necessarily be sensitive to the sedative effects of standard doses of hypnotics in the elderly population, particularly at 11 hours. Our own experience with a number of standard psychomotor tests in elderly individuals has shown that both low baseline scores and abbreviation of tests may result in loss of discrimination. Additionally, it is not stated whether practice effects were minimised by a prestudy regime of familiarisation, a major factor with this particular test. ${ }^{1}$

(2) Sway was not measured between dosing and four hours. The accompanying table shows results of a study in this department of the effects of oral diazepam $10 \mathrm{mg}$ (half-life $20-50$ hours). Sway was significantly increased in elderly volunteers at 0.5 hours and 2.5 hours after dosage, but not thereafter. It is thus possible that interruption or failure of sleep earlier than four hours after benzodiazepine or other hypnotics may be associated with impaired standing steadiness in the elderly. These drugs distribute rapidly to the central nervous system and it has been suggested that, depending on dose, some effects may be limited to the early distribution phase, declining or

Sway after oral diazepam $(10 \mathrm{mg})$ vs placebo (Values are mean scores, with ranges in parentheses)

\begin{tabular}{|c|c|c|c|c|c|c|c|c|}
\hline \multirow[b]{2}{*}{ Time (h) } & \multicolumn{4}{|c|}{ Young subjects (mean age $22 \cdot 1 ; n=11$ ) } & \multicolumn{4}{|c|}{ Elderly subjects (mean age $72 \cdot 4 ; n=12$ ) } \\
\hline & 0.5 & $2 \cdot 5$ & $4 \cdot 5$ & $6 \cdot 5$ & 0.5 & $2 \cdot 5$ & $4 \cdot 5$ & 6.5 \\
\hline $\begin{array}{l}\text { Placebo } \\
\text { Diazepam }\end{array}$ & $\begin{array}{c}9 \cdot 7 \\
(0 \cdot 9-20 \cdot 3) \\
12 \cdot 7 \\
(3 \cdot 2-23 \cdot 8)\end{array}$ & $\begin{array}{c}9 \cdot 7 \\
(1 \cdot 6-22 \cdot 4) \\
12 \cdot 2 \\
(2 \cdot 9-26 \cdot 5)\end{array}$ & $\begin{array}{c}9 \cdot 7 \\
(2 \cdot 7-25 \cdot 2) \\
8 \cdot 4 \\
(3 \cdot 7-17 \cdot 5)\end{array}$ & $\begin{array}{c}9 \cdot 5 \\
(2 \cdot 6-20 \cdot 3) \\
9 \cdot 3 \\
(3 \cdot 9-21 \cdot 5)\end{array}$ & $\begin{array}{c}19 \cdot 8 \\
(6 \cdot 9-34 \cdot 2) \\
31 \cdot 8^{*} \\
(14 \cdot 0-57 \cdot 3)\end{array}$ & $\begin{array}{c}19 \cdot 0 \\
(3 \cdot 7-31 \cdot 3) \\
29 \cdot 4^{*} \\
(12 \cdot 5-61 \cdot 3)\end{array}$ & $\begin{array}{c}19 \cdot 2 \\
(5 \cdot 0-35 \cdot 5) \\
26 \cdot 4 \\
(10 \cdot 8-65 \cdot 4)\end{array}$ & $\begin{array}{c}18 \cdot 9 \\
(4 \cdot 3-34 \cdot 2) \\
18 \cdot 8 \\
(10 \cdot 6-30 \cdot 1)\end{array}$ \\
\hline
\end{tabular}

*Significant difference from placebo ( $p<0.05$; Wilcoxon test for matched pairs). disappearing during the $\beta$-elimination phase (3) determines half-life. ${ }^{2}$

(3) Our experience with visual analogue cales is that elderly volunteers frequently rate themselves optimistically (that is, relatively unimpaired) compared with the young after sedative drugs, even in the presence of measurable impairment as judged by objective assessments. This would be consistent with the with the young, "the old were as awake after the two active treatments as after placebo" when roused at four hours, though other explanations are tenable.

Further detailed assessment of both acute and long-term response to hypnotics in the elderly would appear to be necessary in order to substantiate fully the conclusions reached in this study.

Cameron G SwifT JULIA M HAYTHORNE

Pat Clarke

IAN H STEVENSON

University Department of Ninewells Hospital,
Dundee DD1 9 SY

${ }^{1}$ Lawton MP, Cahn B. 7 Nerv Ment Dis 1963;126:550. 1979:63-81.

\section{Examination of abortuses}

SIR,-Dr A J Barson's comments on the examination of abortuses are timely (12 April, p 1055). If, however, they were extended to include spontaneous abortions, their value would be greatly enhanced. Such examination could yield information concerning the impact of various environmental pollutants on the fetus.

As a prospective means of monitoring Aoxious agents in the environment, examination of such spontaneous abortions has inherent advantages over methods based on the study of full-term pregnancy outcome. Since there is a higher frequency of congenital anomalies in spontaneous abortions the size of the sample necessary to demonstrate the statistically significant change in risk of teratogenesis can be considerably reduced. Concentration on fetal wastage in early pregnancy confers a distinct time advantage over studies based on neonates. The confounding effect of many related factors influencing the fetus in utero are minimised. Exposure to putative agents at critical times can also be assessed with a reasonable degree of reliability. The relative ease by which the abortus may be examined is a contributory factor to its superiority over anything that may be possible in later pregnancy. The epidemiological surveillance of spontaneous abortion may prove to be a powerful investigative tool in the study of teratogenesis and related pathological processes. Other problems inherent in the assessment of community environmental exposures otherwise anomalous finding that, in contrast 